\title{
Effects of Repetitive Horticultural Activities on Kindergarteners' Dexterity and Out of Seat Behavior
}

\author{
Byung Jin Choi, Shin Yu Lee, Tae Young Kwak, and Suk Young Yun* \\ Department of Horticulture, Daegu Catholic University, Gyeongsan 38430, Korea
}

\begin{abstract}
The purpose of this study was to examine the effects of repetitive horticultural activities on the dexterity and out of seat behaviors of 5 years old children. Horticultural activities were conducted from March 3 to April 21, 2017, once a week for 20 minutes per session, a total of 8 sessions. The program was divided into first half (Sessions 1-4) and second half (Sessions 5-8) and horticultural activities were repeatedly carried out. In Sessions 1 and 5, kindergarteners transplanted succulent plants into pots, and observed and managed the plants daily. From Session 2 to 4 and from Session 6 to 8, kindergarteners watered and observed the succulent plants planted in Sessions 1 and 5 and they put flowers on a floral foam $(10 \times 10 \times 10 \mathrm{~cm})$. This study conducted the O'Connor Tweezer Dexterity Test in which the number of pins subjects inserted for 30 seconds was counted, and there was a significant difference $(p=.000)$ in the dexterity of the kindergarteners after performing horticultural activities in the result of the repeated measures design ANOVA. The time kindergarteners left their seat for the first time while participating in horticultural activities for 20 minutes was measured using a stopwatch in each session. There was a significant difference $(p=.000)$ in the ANOVA test in changes in their out of seat behavior in Session 8. In addition, there was no significant difference in the dexterity and out of seat behavior of kindergarteners from Session $2(p=.364, p=$ .975 , respectively) to Session $3(p=.055, p=.283)$, but there was a significant difference from Session 4 ( $p=.042$, $p=.009)$ to Session $8(p=.000, p=.000)$ as sessions were repeated.
\end{abstract}

Keywords: floral foam, O'Connor Tweezer Dexterity Test, succulent plant

\section{Introduction}

Early childhood is the period of slow growth that begins following the first rapid growth and development period. The muscles of the body rapidly grow for the first 3-4 years, and the thickness of muscular fibers increases for the first 5-6 years, enhancing muscular strength (Kim, 2004). Physical dexterity is an children's fundamental motor skill to move the body in one direction and quickly change the direction, which results in rapid cognitive development (Horn and Weiss, 1991). Dexterity can be quickly improved through practices (Kostelnik et al., 1999).

When toddlers become 4-5 years of age, they can learn special strategies that control learning and problem solving. They become more active in achieving their plans and autonomously use their self-regulation ability (Kim, 2005). Self-

This paper was funded by the research funds of Daegu Catholic University in 2018.

Received: February 2, 2019, Revised: March 12, 2019, Accepted: April 10, 2019

First author: Byung Jin Choi, E-mail: bjchoi@cu.ac.kr, (1) https://orcid.org/0000-0001-8983-544X

*Corresponding author: Suk Young Yun, E-mail: yunesy@hanmail.net, (1) https://orcid.org/0000-0002-5862-0021 
regulation is the process of maintaining their planned behaviors to accomplish a certain purpose. Self-regulation ability is an accidental rule that can control behaviors regardless of pressure that is applied in a certain situation, and this ability starts to develop from early childhood which requires attention ability, the cognitive mediation process that appears within the body of children for self-regulation (S.Y. Lee, 2007).

Children's self-regulation is an ability to properly control their behaviors or emotions according to situations (Kim, 2009). Self-regulation is defined from the perspective of emotional regulation as a tendency to pay attention to tasks and suppress inappropriate behaviors in relation to emotions, motor skills and attentional response (Miech et al., 2001). Children who developed self-regulation can wait and self-control to complete challenging activities, and they can control reflective movements, focus on activities and actively control negative emotions (Kendall and Wilcox, 1979).

Positive behavior support in early childhood education focuses on the prevention of problematic behaviors through an ecological approach that includes the mediation of the environment surrounding Vin an integrated education environment (I.S. Lee, 2007). Children can learn a mutually dynamic sense of stability by observing changes in nature (Relf, 1998). Horticultural activities are effective in improving the emotional intelligence of preschool children (Park and Huh, 2010), inducing changes in positive attitudes towards nature and improving their cognitive and emotional abilities (Yu, 2005). For this reason, horticultural activities can be utilized in the curriculum of preschools (Nam, 2008). Since infancy is a critical time for the development of the brain and the formation of behaviors, children must have direct experiences with nature (Schicker, 1988). In addition, as they are emotionally sensitive, the educational effects of nature or horticultural activities are highest in this period (DeMarco et al., 1999).

Living nature has a power to directly educate humans, and it is necessary for children to contact and learn from nature for physical and psychological effects (Montessori, 2009). Nature-friendly education focusing on activities that involve flowers and trees have a positive impact on the whole-rounded development of infants by inducing an positive attitude that makes children become an agent of their activities, a sensitive viewpoint on natural objects and an attentive attitude (Oh, 2011).

Against this backdrop, this study measured children's ability to put pins into a small hole and the frequency of leaving their seats within a certain period of time before and after repeatedly performing horticultural activities in order to examine the effects of horticultural activities on their dexterity and self-regulation behavior.

\section{Research Methods}

\section{Subjects}

There is a study that found that horticultural activities utilizing green plants as a medium were effective for emotional regulation in 5 years old children (Ryu et al., 2013), and based on the result, this study selected kindergarteners who were 5 years old as a subject. Newsletters were sent to the parents of a total of 15 children who were enrolled in kindergarten class in a preschool located in $\mathrm{J}$ city to obtain consent from them, and 10 children (five males and five females) who was not absent during the period of this study and participated in all the eight sessions of the program used in this study, and completed pre- and post-program evaluation were selected as the final subjects of this study.

\section{Tools}

\section{Program design}

Repetitive experiences enhance kindergarteners' emotional intelligence, in particular, its several sub-elements such as 
self-recognition, self-regulation, recognition of others, and an ability to control others (Park, 2012). In this regard, this study repeatedly conducted horticultural activities and those activities were divided into the Sessions 1-4 and Sessions 5-8.

Those who have experiences of growing plants by themselves feel a sense of intimacy toward plants (Linerberger and Zajicek, 2000), and touching the soil with the hands to grow living plants and observing them consume a significant amount of calories, which is effective in improving physical functions, similar to the effects of exercises (Mattson, 1991). In addition, activities such as decorating with flowers increase participants' sense of stability and reduce their stress level (Tak, 2004), and those such as trimming, cutting, bending and arranging flowers activate physical functions, give a sense of emotional stability and also reduce stress, while increasing concentration (Jeong and Han, 2008). In this regard, the program used in this study was designed to have activities including touching the soil to plant plants in pots and caring plants after that in order to improve participants' dexterity, and arranging flowers in order not only to activate physical functions but also to improve concentration, and thus to reduce their out of seat behavior. In the Session 1 and Session 5, participants were instructed to transplant succulent plants into pots and to observe and care them everyday. From Sessions 2-4 and from Sessions 6-8, the succulent plants planted in pots were observed and watered, and flowers were arranged on a floral foam $(10 \times 10 \times 10 \mathrm{~cm})$. Participants were guided to freely put flowers, the same ones that a therapist held up, on a certain-sized floral foam. Cut-flowers used in this study include Rosa hybrida, Ruscus aculeatus, Chrysanthemum morifolium, Ruscus aculeatus, Dianthus caryophyllus, Ruscus aculeatus (Table 1).

\section{Program implementation}

Horticultural activities were performed once a week from March 3 to April 21, 2017, a total of eight sessions. Each program was carried out for 20 minutes, and activities was led by a welfare horticultural therapist, and assisted by the homeroom teacher of the kindergarten class and two trainees. A bell to start and end the program rang to ensure children can be aware of the exact length of class and concentrate on the activities.

\section{Measuring tools}

To examine the effects of horticultural activities on the dexterity and out of seat behavior of kindergarteners, data were collected through the participant observation of the authors of this study and the homeroom teacher. Participant observation is known to provide basic data for identifying valuable data and controling problematic behaviors (Hendrick, 1997). To identify changes in a child's dexterity after participating in horticultural activities, the O'Connor Tweezer Dexterity Test (Lafayette instrument, USA) was conducted after each session to observe how many pins a child put into a

Table 1. Horticultural activity program implemented in this study

\begin{tabular}{|c|c|c|c|c|c|}
\hline \multicolumn{4}{|c|}{ Session } & \multirow{3}{*}{ Activity } & \multirow{3}{*}{ Plant material } \\
\hline \multicolumn{2}{|c|}{ 1st half } & \multicolumn{2}{|c|}{ 2nd half } & & \\
\hline No & Date & No & Date & & \\
\hline 1 & March 3 & 5 & March 31 & Planting plants in a pot & Sedum lucidum \\
\hline 2 & March 10 & 6 & April 7 & Watering and flower arrangement & Rosa hybrida, Ruscus aculeatus \\
\hline 3 & March 17 & 7 & April 14 & Watering and flower arrangement & Chrysanthemum morifolium, Ruscus aculeatus \\
\hline 4 & March 24 & 8 & April 21 & Watering and flower arrangement & Dianthus caryophyllus, Ruscus aculeatus \\
\hline
\end{tabular}


hole with his or her fingers within a certain period of time (30 seconds). Kindergarteners were instructed to participate in each session without leaving their seat after the bell to start the class rang in order to examine changes in their out of seat behavior. The first time a child left his or her seat was measured using a stopwatch in each session. The out of seat behavior in this study meant an act of rising from a chair and moving more than one step away from it.

\section{Data analysis}

Data collected in each session were analyzed using SPSS 19.0 program. Differences between values evaluated in each session from Sessions 1 to 8 were verified using the repeated measures design ANOVA. As a post-hoc analysis, differences between the average values of each session in which horticultural activities were performed were compared with that of Session 1 using a paired comparison analysis between Session 1 and Sessions 2-8.

\section{Results and Discussion}

\section{Changes in dexterity}

Changes in the dexterity of kindergarteners after performing horticultural activities in each session were examined, and the number of flowers that kindergarteners put in the Session 1 on average was 3.9; Session 2, 5.1; Session 3, 5.5; Session 4, 6.1; Session 5, 6.4; Session 6, 7.1; Session 7, 7.7; and Session 8, 7.8. Differences between values measured in each session were verified using the repeated measures design ANOVA, and there were significant differences in the results (Figure 1, $p=.000$ ).

\section{Changes in out of seat behaviors}

The first time kindergarteners moved out of their seat during horticultural activities in each session was measured, and the results showed that the time increased session after session as follows: Session 1, 190 seconds; Session 2, 206 seconds;

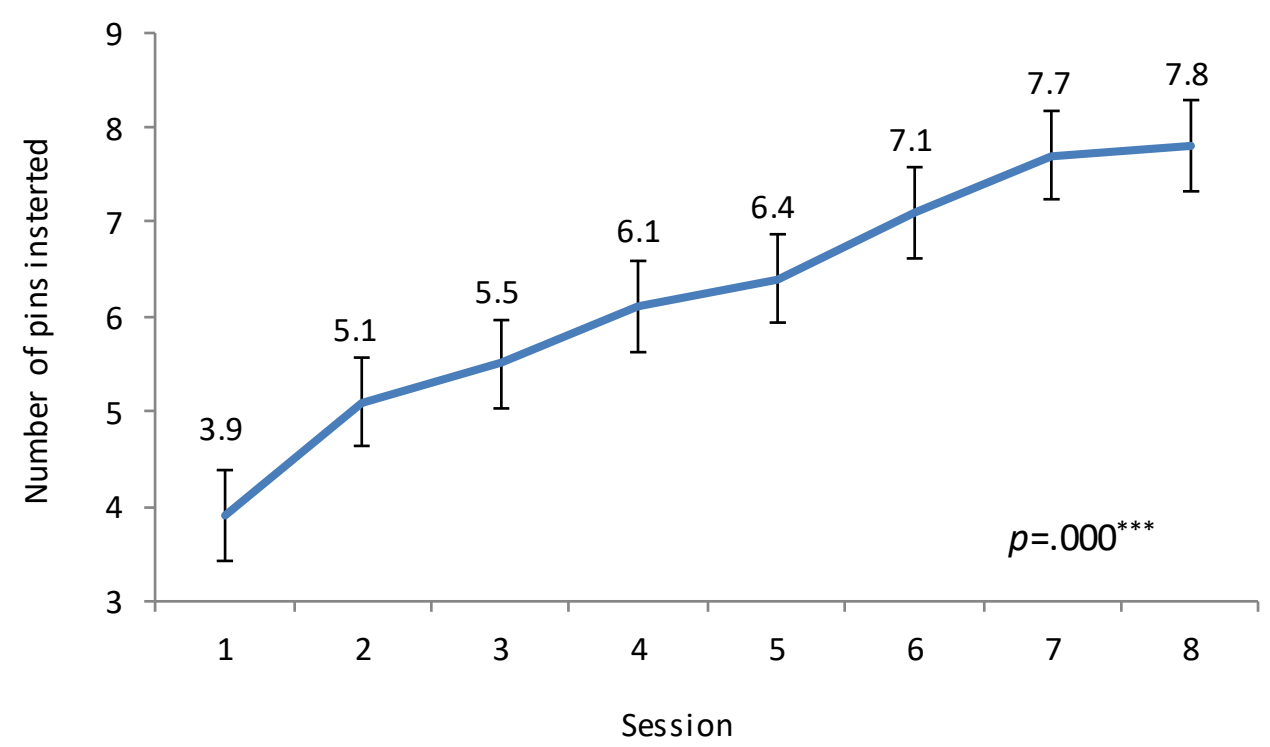

Figure 1. Changes in the dexterity of kindergarteners in each session during horticultural activities program. Three asterisks denote significant differences at $p<.001$ by repeated measures design ANOVA. Bars mean standard error. 
Session 3, 216 seconds; Session 4, 241 seconds; Session 5, 253 seconds; Session 6, 276 seconds; Session 7, 310 seconds; and Session 8, 332 seconds. In other words, as kindergarteners participated in more sessions, the length of time kindergarteners were able to concentrate on activities without leaving their seat gradually increased. Differences between values measured in each session were verified using the repeated measures design ANOVA, and there were significant differences (Figure 2, $p=.000$ ).

\section{Paired comparison between sessions}

To compare differences between the average value measured in Session 1 and that measured in other sessions, data collected in each session (Sessions 2-8) were compared with those collected in Session 1 by pairing the data (Table 2). In terms of changes in dexterity, there was no significant difference in Session $2(p=.364)$ and Session $3(p=.055)$. There was a significant improvement in Session 4 ( $p=.042)$, and drastic improvements were observed session after session as follows: Session 5, $p=.007$; Session 6, $p=.001$; Session 7, $p=.000$; and Session 8, $p=.000$. In terms of the time to move out of seats, there was also no significant difference in Session $2(p=.975)$ and Session $3(p=.283)$, but a significant improvement was observed in Session 4 ( $p=.009)$. Drastic improvements were observed session after session as follows: Session 5, $p=.003$; Session 6, $p=.000$; Session 7, $p=.000$; and Session 8, $p=.000$ (Table 2). In other words, participating children concentrated better on horticultural activities without leaving their seat session after session compared to Session 1.

As Kostelnik et al. (1999) pointed out that the dexterity of children among other basic motor skills can be rapidly improved through repetitive exercises, the results of this study also showed that the dexterity of 5 years old was improved by repetitively performing simple activities such as watering and putting flowers on a floral foam in each session. As a tool to measure the dexterity of kindergarteners, they were instructed to put pins on a designated space, and the number of pins that they put increased session after session, which corresponded with the conclusion of Haywood (1986) that physical movements can develop children's ability to perceive the shape and depth of objects.

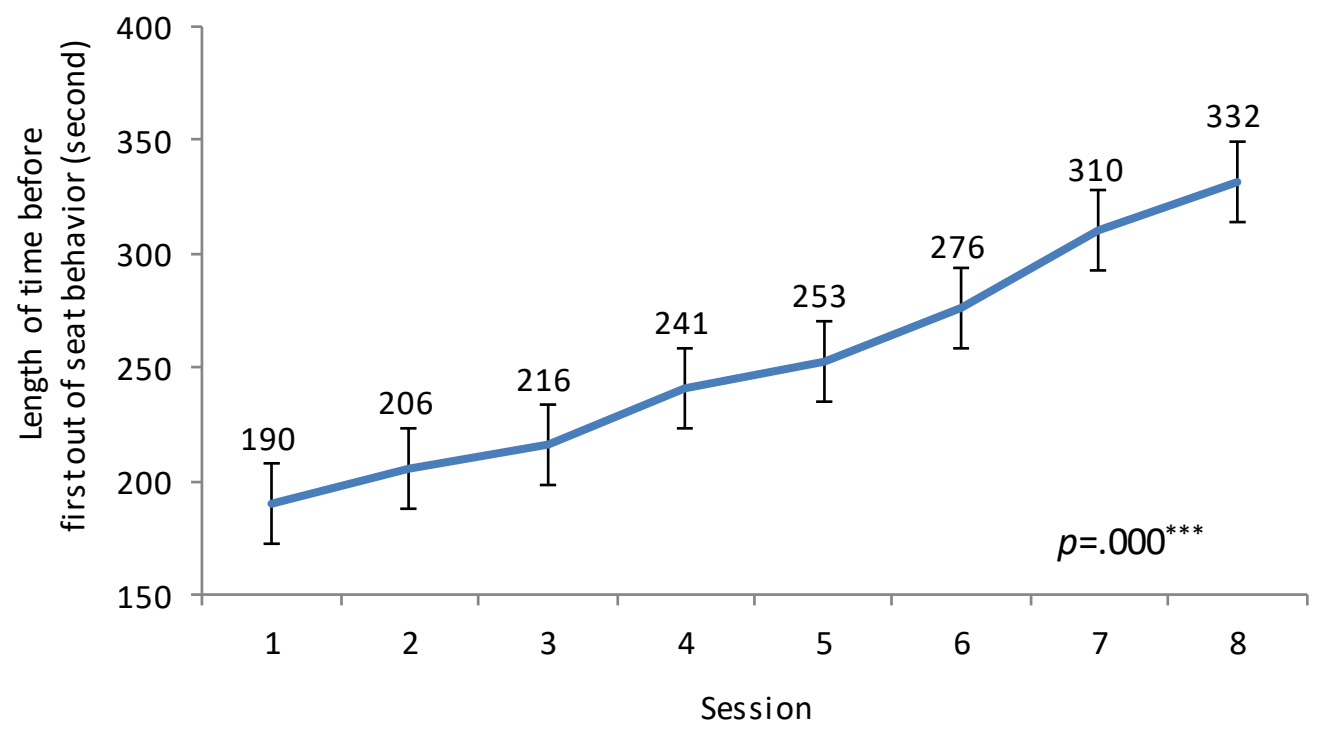

Figure 2. Changes in the time of first occurrence of out of seat behavior of kindergarteners in each session during the horticultural activity program. Three asterisks denote significant differences at $p<.001$ by repeated measures design ANOVA. Bars mean standard error. 
Table 2. Comparative analysis of correspondence of Sessions 2-8 from Session 1

\begin{tabular}{|c|c|c|c|c|c|}
\hline Item & Session (I) & Session $(J)$ & Average difference (I-J) & $\mathrm{SE}$ & $p$ \\
\hline \multirow{7}{*}{ Dexterity } & \multirow[t]{7}{*}{1} & 2 & -1.200 & 0.389 & $.364^{\mathrm{NS}}$ \\
\hline & & 3 & -1.600 & 0.371 & $.055^{\mathrm{NS}}$ \\
\hline & & 4 & -2.200 & 0.490 & $.042^{*}$ \\
\hline & & 5 & -2.500 & 0.428 & $.007^{* *}$ \\
\hline & & 6 & -3.200 & 0.442 & $.001^{* *}$ \\
\hline & & 7 & -3.800 & 0.416 & $.000^{* * * *}$ \\
\hline & & 8 & -3.900 & 0.379 & $.000^{* * * *}$ \\
\hline \multirow{7}{*}{ Out of seat behavior } & \multirow[t]{7}{*}{1} & 2 & -0.267 & 0.108 & $.975^{\mathrm{NS}}$ \\
\hline & & 3 & -0.400 & 0.123 & $.283^{\mathrm{NS}}$ \\
\hline & & 4 & -0.773 & 0.137 & $.009^{* *}$ \\
\hline & & 5 & -0.928 & 0.144 & $.003^{* *}$ \\
\hline & & 6 & -1.403 & 0.164 & $.000^{* * * *}$ \\
\hline & & 7 & -1.898 & 0.222 & $.000^{* * * *}$ \\
\hline & & 8 & -2.282 & 0.267 & $.000^{* * * *}$ \\
\hline
\end{tabular}

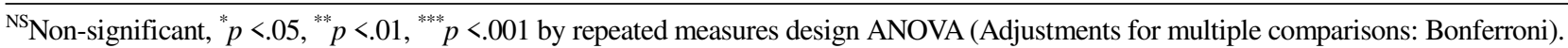

\section{Conclusion}

This study was conducted to examine the effects of horticultural activities on the dexterity and out of seat behaviors of 5-year-old children, two of their basic motor skills. Simple and repetitive horticultural activities were performed for 20 minutes in each of eight sessions. The first time infants moved out of their seat was measured, and changes in their dexterity were measured after the activities by counting how many pins they were able to put into a small hole for 30 seconds. There was no significant difference in their dexterity and out of seat behavior for the first three sessions, but more significant effects started to be observed session after session from the 4th to the 8 th session. These results indicate that living plants have a power to attract humans, and repetitive exercises increase the effect, and that various types of activities that involve natural objects need to be engaged for children' healthy cognitive, emotional and physical development. In order to verify the clear effects of horticultural activities, it is necessary to compare a control group and an experimental group and thus to obtain more specific results. This study, however, showed some limitations such as generalizing the results of an experiment on a small amount of subjects without setting a control group.

\section{References}

DeMarco, L.W., D. Relf, and A. McDaniel. 1999. Integrating gardening into the elementary school curriculum. HortTechnology 9(2):276-281.

Haywood, K. 1986. Life span motor development. Champaign, IL: Human Kinetics.

Hendrick, J. 1997. First steps toward teaching the Reggio way. Upper Saddle River, NJ: Merill.

Horn, T.S. and M.R. Weiss. 1991. A developmental analysis of children's self-ability judgments in the physical domain. Pediatr. Exerc. Sci. 3(4):310-326. https://doi.org/10.1123/pes.3.4.310

Jeong, H.I. and I.J. Han. 2008. A study on the methodology of analysis for the five senses development of children by 
flower arrangement. J. Korean Soc. Flor. Art Des. 18:89-118.

Kang, H.Y. 2004. The effect of horticultural activity program on children's aggressiveness. Master's thesis, Jeju National University, Jeju, Korea.

Kendall, P.C. and L.E. Wilcox. 1979. Self-control in children: Development of a rating scale. J. Consult. Clin. Psychol. 47(6):1020-1029. https://doi.org/10.1037/0022-006X.47.6.1020

Kim, H.K. 2005. The relation between parental role of mother and infant self regulation. Master's thesis, Sookmyung Women's University, Seoul, Korea.

Kim, S.J. 2009. A study on the effects of children temperament and parenting attitude on children's self-regulation. Master's thesis, Kyungwoon University, Gumi, Korea.

Kim, S.K. 2004. An influence the tool-playing and the apparatus gymnastics for infants has on the development of physical strength. Master's thesis, Kyonggi University, Seoul, Korea.

Kostelnik, M.J., A.K. Soderman, and A.P. Whiren. 1999. Developmentally appropriate curriculum: Best practices in early childhood education. Upper Saddle River, NJ: Prentice Hall.

Lineberger, S.E. and J.M. Zajicek. 2000. School gardens: Can a hands-on teaching tool affect student's attitudes and behaviors regarding fruit and vegetables? HortTechnology 10(3):593-597.

https://doi.org/10.21273/HORTTECH.10.3.593

Lee, I.S. 2007. The effects of class-wide positive behavior support on the behavior of students with developmental disabilities and the interactive behavior of the peers. J. Spec. Educ. 14(1):193-214. Retrieved from https://www.nise.go.kr/

Lee, S.Y. 2007. A study on character and guidance of infant's basic living habit. Master's thesis, Kyungwoon University, Gumi, Korea.

Mattson, R.H. 1991. Exploring a specific application: Prescribing health benefits through horticultural activities. In: D. Relf (Ed.), The role of horticulture in human well-being and social development: A national symposium (1990 proceedings, pp. 161-168). Portland, OR: Timber Press.

Miech, R., M.J. Essex, and H.H. Goldsmith. 2001. Socioeconomic status and the adjustment to school: The role of self-regulation during early childhood. Sociol. Educ. 74(2):102-120. https://doi.org/10.2307/2673165

Montessori, M. 2009. The Montessori method. Radford, VA: Wilder Publications.

Nam, S.J. 2008. Effects of the weekend horticultural activity program based upon the kindergarten curriculum on the change of maternal rearing attitude and the inquiry area in children. Master's thesis, Konkuk University, Seoul, Korea.

Oh, Y.H. 2011. Meanings of nature-friendly early childhood curriculum on children's development: Focusing on 'Flower and tree' related activities. J. Korea Open Assoc. Early Child. Educ. 16(1):47-70.

Park, S.H. and M.R. Huh. 2010. Effects of a horticultural program on the preschool children's emotional intelligence and daily stress. Korean J. Hortic. Sci. Technol. 28(1):144-149.

Park, Y.H. 2012. The effects of repeated experiences of stories on young children's emotional intelligence. Korean J. Early Child. Educ. 14(2):35-63.

Relf, D. 1998. The role of horticulture in human well-being and quality of life. J. Korean Soc. People Plants Environ. 1(1):12-20.

Ryu, S.H., Y.Y. Park, and S.W. Lee. 2013. The effects of gardening activities promoting nature-experience on young children's emotional intelligence and nature-friendly attitude. Korean Educ. Inquiry 31(3):1-20.

Schicker, L. 1988. Planning for children and wildlife begins at home. J. Environ. Educ. 19(4):13-21.

Tak, Y.S. 2004. The effect of horticultural therapy using the flower arrangement in center: Terminal cancer patients. Master's thesis, Honam University, Gwangju, Korea.

Yu, H.M. 2005. An examination of attitude and concept comprehension process of nature by 3 year old children seen through nature play experience. Master's thesis, Chung-Ang University, Seoul, Korea. 